\title{
Effective Usage of Gamification Techniques to Boost Student
} Engagement

\author{
Ragesh Raju ${ }^{1}$, Sathyendra Bhat ${ }^{2}$, Shreeranga Bhat ${ }^{3}$, Rio D'Souza ${ }^{4}$, Athokpam Bikramjit Singh ${ }^{5}$ \\ ${ }^{1}$ Department of Computer Applications, St Joseph Engineering College, Mangaluru, Karnataka, India \\ ${ }^{2}$ Department of Computer Applications, St Joseph Engineering College, Mangaluru, Karnataka, India \\ ${ }^{3}$ Department of Mechanical Engineering, St Joseph Engineering College, Mangaluru, Karnataka, India \\ ${ }^{4}$ Department of Computer Science and Engineering, St Joseph Engineering College, Mangaluru, Karnataka, India \\ ${ }^{1}$ rageshr@sjec.ac.in \\ ${ }^{2}$ sathyendrab@sjec.ac.in \\ ${ }^{3}$ shreerangab@sjec.ac.in \\ ${ }^{4}$ riod@sjec.ac.in \\ 5bikramjits@sjec.ac.in
}

\begin{abstract}
:
As the engineering education fraternity is getting accustomed to the new normal amidst the global COVID19 pandemic, online teaching has been gaining much attention in the recent past. While teachers are getting adjusted to this new way of teaching, it is paramount that the teaching-learning process caters to the needs of our millennial learners. Considering all these factors, the teacher must continuously work towards always keeping the students motivated. The authors of this paper brought in a series of innovative gamification constructs throughout a semester across multiple courses to gauge the level of involvement of students during the online lectures as well as the Learning Management System (LMS). The motive was the ensure that the students actively participate in all deliberations, thereby positively impacting the online learning process. The participants of the study were 56 second year Post Graduate students who were undergoing online classes. Several tasks, as well as assessments, were assigned to the students. While doing so, students were introduced to new gamification tools like Mentimeter, Edpuzzle, Kahoot, Quizizz and many more at regular intervals to break the monotony and keep them on their feet waiting for the next task to be performed. This not only meant that the students started participating in the classes more actively but also kept them engaged with a variety of innovative tools. The results clearly showed that the students started learning the concepts better while keeping competitive spirits. When it came to individual activities, there was an urge in students to outperform each other, which meant that the students would go that extra mile to get the things done. At the same time, team tasks had a high level of collaboration resulting in effective learning and building camaraderie. The students prefer learning through multiple sources and multiple platforms. By leveraging technological advancements and bringing in gamification in learning, the overall teaching-learning process gets highly benefited.
\end{abstract}

Keywords: Gamification, Technology, Online TeachingLearning, Student Engagement and Motivation

\section{Introduction}

Student engagement is known as an essential attribute to influence students' achievement. Students' prior learning (readiness), enthusiasm for learning, and the way the input is introduced to them are some of the factors that influence their ability to learn (Eltegani and Butgereit, 2015). Diverse learning styles among the students also contribute to the way they engage in the activities conducted by the educators. Sustaining the students' interest and participation is a struggle that leaves the educator in a quandary. This is because students' involvement plays an essential factor in their achievement and performance (Handelsman et al., 2005) measured during either the formative or summative assessment. (Mohd et al., 2016) found that active students are more likely to perform well as they retained more knowledge during learning activities. Several studies referred to gamification as a technique to increase the students' engagement (Hanus and Fox, 2015), (Kuo and Chuang, 2016), (Sanmugam et al., 2016). Gamification is the use of game design elements in nongame settings to engage participants and encourage desired behaviours. Technological developments allow the use of game elements in a non-game context by extending the methods that can be employed by educators in developing lesson plans. Not all educators are creative enough to include gamification in their lessons. Thus online platforms such as Kahoot!, Quizizz, Socrative, and Quizalize provide excellent options for educators to choose from in diversifies lesson plans and activities that can captivate and inspire students' motivation and increase students' engagement during lessons in the classroom.

The dynamic of games has influenced the popularity of gamification in the effort to enrich students experience in their learning journey, especially in a classroom. This paper explores the effectiveness of gamification technique to improve the students' engagement in database subject implemented in Polytechnic Muadzam Shah Pahang, Malaysia. Following the introduction, Section "Related Study" presents related studies on students' engagement and gamification. This is then followed by Section "The Research Framework and Model" that elaborate on the research framework and model. Sequentially, Section "The 
Empirical Investigation Instruments" describes the empirical investigation instruments to evaluate the gamification effectiveness and Section "Results and Discussion" presents the results and analysis. Finally, Section "Conclusion" concludes the paper.

\section{Literature Review}

There are many definitions arose from numerous studies regarding the term of student engagement. Most literature found, defined student engagement as activities performed either physically or mentally by students in their pursuit to gain knowledge (Dixson, 2015), (Mohd et al., 2016), (Marx et al., 2016). In a different angle, a study by (Hu et al., 2016) define it as engagement that happens when students are using online learning platform in their learning as in this environment; the students themselves can only access the learning materials.

These studies also identify factors that contributed to the students' engagement. (Mohd et al., 2016) and (Hu et al., 2016) stated that students engagement comprised of three dimensions; cognitive, behavioural and emotional engagement. Other studies by (Handelsman et al., 2005), (Dixson, 2015) and (Marx et al., 2016) however categorized student engagement into four factors which are skill engagement (represented by skill displayed by students), emotional engagement (represented by students' feelings), participation (represented by activities done by students in learning) and performance engagement (represented by the result of assessments done by students). Besides, Marx et al. (2016) also listed another engagement which is total engagement to measure the students' perception of their overall engagement in one of the courses taken in the college.

Based on the literature, several significant influences were identified. Relationship between students and educator was found to play a vital role in students' engagement (Mohd et al., 2016), (Marx et al., 2016). Furthermore, (Marx et al., 2016) also stated that educators' expectation for the students to be engaged in the classroom could be met if the educators themselves reciprocate this expectation towards the students.

Today, the wealth of technologies available in the world of education makes traditional learning (chalk and talk method) more and more marginalized. This method of learning is considered to be teacher-oriented and becoming increasingly less used by today's educators. In recent years, the concept of gamification in education is gaining a foothold as an area of study among researchers. Researchers describe gamification as an infusing game component into a non-game context (Hanus and Fox, 2015), (Kuo and Chuang, 2016) which can be used as a mean to promote student engagement in the classroom (Hamari, 2015), (Hanus and Fox, 2015), (Sanmugam et al., 2016). Leaderboard, badges, points and levels are some of the game elements employed in previous studies (Barata et al., 2013), (Hamari, 2015), (Hanus and Fox, 2015), (Kuo and Chuang, 2016), (Sanmugam et al., 2016). According to Table 1, badges are the top choice of researchers to be used in the gamification being implemented, followed by the leaderboard. This may be caused by users' perception that badges will highlight their social status to their peers (Hamari, 2015). Although most studies found that gamified learning has a positive impact on student engagement (Barata et al., 2013), (Hamari, 2015), (Kuo and Chuang, 2016), (Sanmugam et al., 2016), the discovery from (Hanus and Fox, 2015) contradict this finding. (Hanus and Fox, 2015) found that over time, students experiencing gamified learning showed a decline in their motivation, thus affecting their final exam scores. The researchers attribute this decline to the expiration of novelty of the method used as the research was conducted over 16 weeks. This led to the conclusion that any gamification undertook must be considered with great care as to it not being detrimental to the students as opposed to helping them in their learning.

Some researchers also study the gamification platforms which use web-based students' response systems such as Kahoot! and Quizizz (Wang 2015), (Wang and Lieberoth, 2016), (Chaiyo and Nokham, 2017), (Sawang et al., 2017). (Wang, 2015), found that Kahoot! Implementation is a different situation (event and semester) by two groups of students produce the same result as both groups agree that the game is still engaging irrespective of the duration they were using the Kahoot!. The students similarly found that the interactive and fun way of learning provided by Kahoot! increased their determination in winning the game, which helped their engagement in class. Thus, (Wang, 2015) concluded that the duration of gamification did not affect negatively on the students' engagement. In another study, (Wang and Lieberoth, 2016) expanded the research by studying the effects of game elements such as audio and points in Kahoot! Towards students' engagement. The result indicates that although the use of audio does have a positive impact on students' interaction, the combination of both audio and points gave a much more significant effect as they provide positive classroom dynamics (Wang and Lieberoth, 2016).

In contrast, (Chaiyo and Nokham, 2017) studied the effects of three different gamification tools to the students' engagement, enjoyment, concentration, perceived learning, satisfaction and motivation in lessons. They found that although all the three tools, which are Kahoot!, Quizizz and Google Form, did not show any variance on how the students perceived their learning, the students were more biased towards Kahoot! Moreover, Quizizz in comparison to Google Form as they agree that Kahoot! and Quizizz can improve their concentration, engagement, enjoyment and motivation (Chaiyo and Nokham, 2017).

\section{Methodology}

With the increase in the intensity of online classes, teachers around the world have switched entirely to the online mode of teaching. Typically in an offline class, the teacher can observe the attentiveness of students and decide to bring in some innovative constructs that enable the students to keep their motivation level high. This also contributes to the increase in student engagement in the physical classroom. However, this sort of approach seems almost impossible in an online environment where the teacher cannot have a face- 
to-face dialogue with the student and monitor the progress of all students.

To overcome this situation, the authors of this paper tried out several innovative online tools to keep the students engaged and motivated throughout. While most of these tools worked well with the students, different tools were used so that students will not get biased towards a single online tool. This ensured that the students were kept waiting on their toes to experience a new tool in each of the classes. This way, the authors were able to bring in a surprise element which meant that the students do not get accustomed to a single tool and lose interest in the overall teaching-learning process.

\section{A. Participants}

The participants for this study were 56 second year, fulltime students from the postgraduate department in computer applications and two teachers of the same department. Due to this nationwide lockdown caused due to the pandemic situation, the participants were forced to attend online classes sitting at remote locations with literally no face-to-face communication with the teacher.

\section{B. Study Design}

As a first step, the main group was created for the entire class on the popular messenger application, Telegram, wherein instructions/information related to the course were given, and materials were posted at regular intervals. In addition to the Telegram group that was created for easy communication, a class was created on the popular Learning Management System, Google Classroom (Bhat et al., 2018).

While the Telegram group was intended to allow the teacher to communicate with the class effectively, eight subgroups were created with the help of Pickerwheel.com, an online randomized team creator. All these teams were made to create a WhatsApp group with their respective team names, and the teacher was added as one of the admins.

Throughout the semester, for each activity posted in the main Telegram group as well as the Google Classroom LMS, students were instructed to have teamwise discussions in the respective WhatsApp groups which were monitored by the teacher. In case if the groups ran into any issues, the teacher was there to ensure that the issue gets resolved on time and the discussions continue without or with minimal hassles. Post discussions, the teams were made to post the solutions in individual groups, allowing the teacher to evaluate the submission and decide the winners accordingly.

This arrangement worked well for sometime before the students getting complacent and some members in the teams not collaborating with the rest to get the work done. However, this was overcome by breaking the monotony in the teams. The team members were shuffled using Pickerwheel.com after every internal test so that new teams get formed which would again start to work afresh. This also allowed the teacher to assess each student's participation across multiple teams, thereby giving the teacher a better idea about the motivation level among each of the students. Before shuffling the teams, the scores for the individuals in a team as well as the scores for the team itself were calculated by adding all the cumulative scores which were instrumental in deciding the giving away the of the badges. Also, due care was taken to ensure that the teams do not get shuffled for more than two times during the entire semester.

The classical concept of any gamified learning environment, Experience Points (XP) was brought in, and the students were given XP for participating in each activity apart from the regular scores. This assisted in boosting the confidence level of the students and help in keeping them motivated.

Polls were conducted in the classes at regular intervals to break the monotony of straight lectures. Even though the classes had moved online, the class timings were sill 55 minutes each for each of the lectures which had to be utilized judiciously. The pools were conducted using tools like Mentimeter, Strawpoll, AhaSlides, Poll Everywhere, Slido, etc. so that learners get a flavour of each of these polling tools. Table 1 shows the comparison of various polling tools that were used during the online classes. The comparison is in terms of the audience, the number of questions allowed, the number of quizzes allowed, the option for Q\&A and versions available.

Table 1. Comparison of polling tools

\begin{tabular}{|c|c|c|c|c|c|}
\hline Tool & Audience & No. of Questions & No. of Quizes & Q\&A & Version Available \\
\hline Mentimeter & No Limit & 2 & 5 & No Limit & Paid \\
\hline StrawPoll & No Limit & 1 & 0 & 0 & Free \\
\hline AhaSlides & 7 & No Limit & No Limit & No Limit & Paid \\
\hline Poll Everywhere & 40 & No Limit & 0 & 0 & Paid \\
\hline Slido & 1000 & 5 & 1 & No Limit & Paid \\
\hline
\end{tabular}

Along with the quick in-class polls, the students also had to be assessed with the help of small quiz based assessments. Several Multiple Choice Questions (MCQ) based quizzes were dished out to students with the help of tools like Canvas Quiz, Google Form Quiz, Kahoot and Quizizz. The reasons for using different tools for conducting quizzes was to give the students a feel of different types of assessment, which was ranging from a regular online assessment to a more engaging and interactive gamified assessment environment that has been compared in Table 2 .

Table 2. Comparison of quizzing tools 


\begin{tabular}{|c|c|c|c|c|c|}
\hline Tool & Audience & Gamified & Full Features & Quiz Timer & Group Creation \\
\hline Canvas Quiz & No Limit & No & Yes & Yes & Yes \\
\hline Google Form & No Llmit & No & No & No & No \\
\hline Kahnoot & Class Size & Yes & No & Questionwise & Yes \\
\hline Quizziz & No Limit & Yes & No & Questionwise & Yes \\
\hline
\end{tabular}

In addition to the above, online classes were conducted by using Google Meet, Zoom and Cisco Webex Meetings to allow the students to have a first-hand experience of various online meeting platforms.

To go with the online meeting tools, presentations were made by using Microsoft Powerpoint, Google Slides, Mentimeter and Quizizz Lessons to give an insight into different possibilities of technical presentations.

Although conduction of online classes was practised regularly, the students were also exposed to offline recorded video lectures that were shared with the students using YouTube and Edpuzzle to show how each view can be tracked and assessed.

Alongside the rest of the resources, readings/videos were posted on the Google Classroom as well as the Telegram group. To ensure that the students go through the reading as well as video resources, Crossword puzzles were created using crosswordlabs.com which compelled the students to go through the reading or watch the videos so that they could solve the crossword puzzle to earn reward points.

The free versions of all the tools were leveraged for conduction of online classes. The comparison shown in Table 1 and Table 2 were for the free/limited period versions only.

\section{Results and Discussion}

Having leveraged all the innovative tools, their effectiveness was to be evaluated. To assess the performance of these tools, several online surveys were conducted throughout the semester. The student engagement across all the tools is shown in Fig 1.

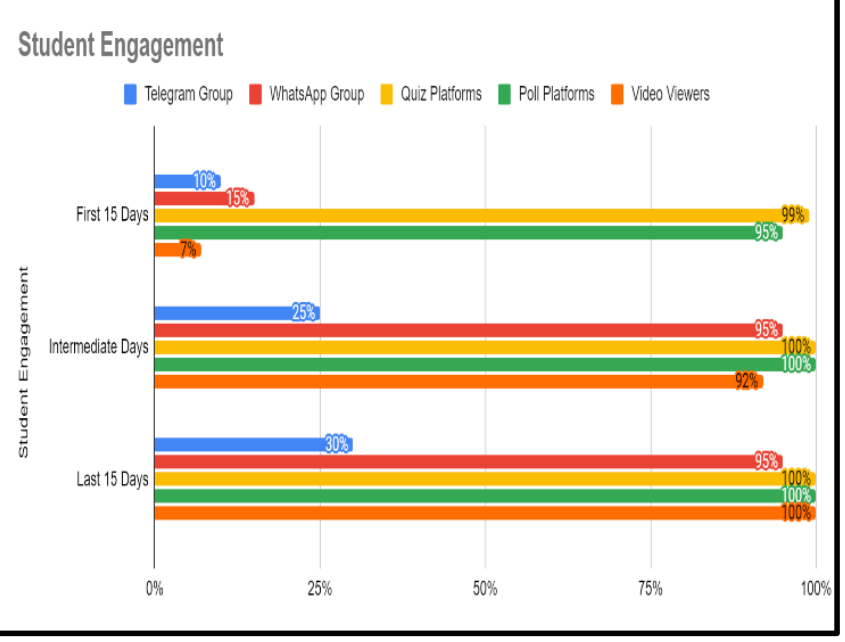

Fig. 1: Student engagement across all teaching-learning tools

As it is quite evident from Fig 1, students gradually developed their interest towards each of these tools as the semester progressed. While students were more inclined towards the quizzes and the polls in the first 15 days, their experiences with each of these tools made sure that their engagement increased during the intermediate days. Towards the end of the semester, a whopping $100 \%$ engagement was observed in quiz, poll and video views, whereas the engagement in the WhatsApp group also witnessed steady progress. The relatively low engagement on Telegram was because the Telegram group was created with the intention of the teacher posting the course materials.

As far as the voice of the students was concerned, Fig 2 shows that students had a higher inclination towards innovative gamified tools like Kahoot and Quizizz that garnered the most number of 5-star rating points. While Mentimeter and Crosswords were also equally popular, students relatively lower inclination towards Canvas Quiz, Slido and Edpuzzle.

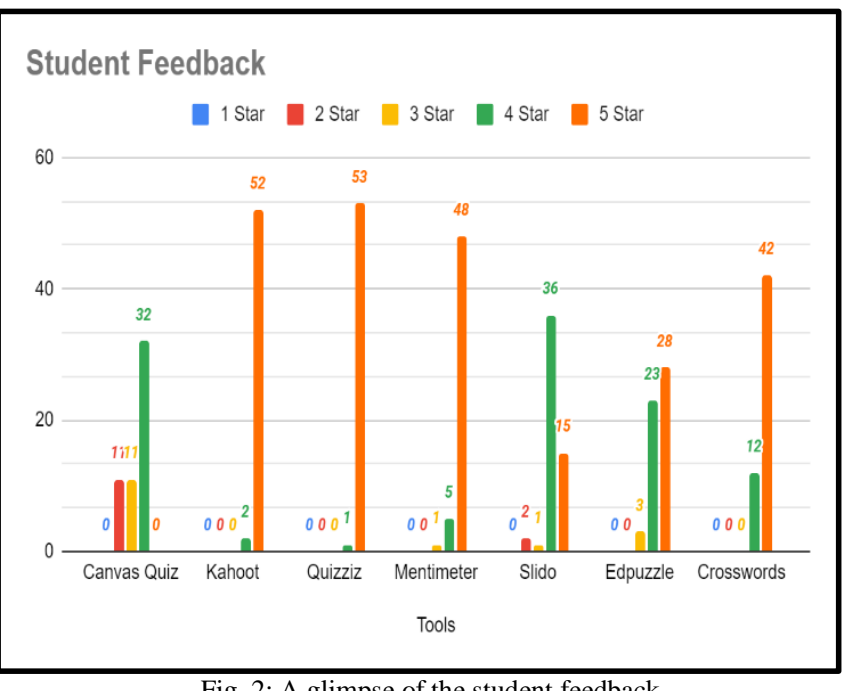

Fig. 2: A glimpse of the student feedback

\section{Conclusion}

Student engagement and motivation has always been an essential factor in the teaching-learning process right from the traditional classroom pedagogy to the present online teaching model. In recent times, more and more classes have been shifted online that has made student engagement even more difficult than before. In a traditional setup, teachers had the freedom to have direct face-to-face communication with all students in the class, which is the missing link in modern online teaching approaches. Hence, managing student engagement becomes a vital factor in online classes. The authors of this paper used a large pool of innovative and exciting online teaching tools to ensure that the students remain engaged and motivated throughout all lectures, be it live lectures or the recorded ones. Google Classroom was also effectively utilized to manage course content and interact with the students regularly. As this study shows, 
students inclination is more towards a game-based learning platform, that brings out the competitive spirit among the students and eventually results in better performances.

\section{References}

Eltegani, N., \& Butgereit, L. (2015, September). Attributes of students engagement in fundamental programming learning. In 2015 International Conference on Computing, Control, Networking, Electronics and Embedded Systems Engineering (ICCNEEE) (pp. 101-106). IEEE.

Handelsman, M. M., Briggs, W. L., Sullivan, N., \& Towler, A. (2005). A measure of college student course engagement. The Journal of Educational Research, 98(3), 184-192.

Mohd, I. H., Aluwi, A. H., Hussein, N., \& Omar, M. K. (2016). Enhancing students engagement through blended learning satisfaction and lecturer support. In Engineers Institute of Electrical and Electronics (IEEE) (Ed.), 2016 IEEE 8th International Conference on Engineering Education (ICEED2016): "Enhancing Engineering Education Through Academia-Industry Collaboration", (pp. 175-180). Red Hook, NY: Curran Associates, Inc Kuala Lumpur, Malaysia, 7 - 8 December 2016.: Kuala Lumpur, Malaysia.

Hanus, M. D., \& Fox, J. (2015). Assessing the effects of gamification in the classroom: A longitudinal study on intrinsic motivation, social comparison, satisfaction, effort, and academic performance. Computers and Education, 80, 152-161.

Kuo, M. S., \& Chuang, T. Y. (2016). How gamification motivates visits and engagement for online academic dissemination - an empirical study. Computers in Human Behavior, 55, 16-27.

Sanmugam, M., Abdullah, Z., Mohamed, H., Mohd Zaid, N., Aris, B., \& Van Der Meijden, H. (2016). The impacts of infusing game elements and gamification in learning. In Institute of Electrical and Electronics Engineers (IEEE) (Ed.), 2016 IEEE 8th International Conference on Engineering Education (ICEED2016): "Enhancing Engineering Education Through Academia-Industry Collaboration", (pp. 131-136). Red Hook, NY: Curran Associates, Inc Kuala Lumpur, Malaysia, 7 - 8 December 2016.: Kuala Lumpur, Malaysia.

Bhat S., D'Souza R., Bhat S., Raju R. and Kumara P. B. (2020a) Effective Deployment of Outcome Based Education: Strategies based on Motivational Models, Journal of Engineering Education Transformation, 33, 164-169.

Dixson, M. D. (2015). Measuring Student Engagement in the Online Course: The Online Student Engagement Scale (OSE). Online Learning Journal, 19(4).

Marx, A. A., Simonsen, J. C., \& Kitchel, T. (2016). Undergraduate Student Course Engagement and the Influence of Student, Contextual, and Teacher
Variables. Journal of Agricultural Education, 57, pp. 212-228.

Hu, M., Li, H., Deng, W., \& Guan, H. (2016). Student Engagement: One of the Necessary Conditions for Online Learning. In Institute of Electrical and Electronics Engineers (IEEE) (Ed.), 2016 International Conference on Educational Innovation through Technology (EITT). Red Hook, NY: Curran Associates, Inc Tainan, Taiwan, 22 - 24 September 2016.

Bhat S., D'Souza R., Bhat S., Raju R., and Binu K. G. (2020b) Collaborative Learning for Outcome Based Engineering Education: A Lean Thinking Approach, Procedia Computer Science, 172, 927936.

Hamari, J. (2015). Do badges increase user activity? A field experiment on the effects of gamification. Computers in Human Behavior, 71, 469-478.

Barata, G., Gama, S., Gonçalves, D., \& Jorge, J. (2013). Improving participation and learning with gamification. In Proceedings of the First International Conference on Gameful Design, Research, and Applications - Gamification 2013, (pp. 10-17). New York: ACM Stratford, Ontario, Canada, 2 - 4 October 2013 Stratford, Ontario, Canada.

Wang, A. I. (2015). The wear out effect of a game-based student response system. Computers \& Education, 82, 217-227.

Bhat, S., Raju R., Bhat S. and D'Souza R. (2020c), Redefining Quality in Engineering Education through the Flipped Classroom Model, Procedia Computer Science, 172, 906-914.

Wang, A. I., \& Lieberoth, A. (2016). The effect of points and audio on concentration, engagement, enjoyment, learning, motivation, and classroom dynamics using Kahoot! In T. Connolly, \& L. Boyle (Eds.), Proceedings from the 10th European conference of game based learning, (pp. 737-748). Paisley: Academic Conferences and Publishing International Limited 6 - 7 October 2016.

Chaiyo, Y., \& Nokham, R. (2017). The effect of Kahoot, Quizizz and Google forms on the student's perception in the classrooms response system. In Institute of Electrical and Electronics Engineers (IEEE) (Ed.), 2017 International Conference on Digital Arts, Media and Technology (ICDAMT), (pp. 178-182). Red Hook, NY: Curran Associates, Inc Chiang Mai, Thailand, 1 - 4 March 2017.

Sawang, S., O'Connor, P., \& Ali, M. (2017). IEngage: Using technology to enhance students' engagement in a large classroom. Journal of Learning Design, 10(1), 11-19.

Bhat, S., Raju, R., Bikramjit, A., \& D'Souza, R. (2018). Leveraging E-learning through Google classroom: A usability study. Journal of Engineering Education Transformations, 31(3), 129-135. 